\title{
CORRIGENDUM
}

\section{Correlated contemporary evolution of life-history traits in New Zealand Chinook salmon, Onchorhynchus tshawytscha}

MT Kinnison, TP Quinn and MJ Unwin

Heredity (2011) 106, 906; doi:10.1038/hdy.2011.28

Correction to: Heredity (2011) 106, 448-459; doi:10.1038/ hdy.2010.162

Upon publication in the 'Genetics of local adaptation in salmonid fishes' Special Issue in the March 2011 volume of Heredity, the authors of the above paper noted an error in their affiliations. The affiliations for Drs Quinn and Unwin were reversed in the published version. Both the publishers and authors are happy to correct this error, below:

Thomas Quinn is at the School of Fisheries and Aquatic Sciences (University of Washington, Seattle, WA, USA) and Martin Unwin is at the National Institute of Water and Atmosphere Research (Christchurch, New Zealand). 